\title{
AS DESIGUALDADES SOCIOESPACIAIS DE ACESSO AOS SABERES: UMA PERSPECTIVA DE RENOVAÇÃO DA SOCIOLOGIA DAS DESIGUALDADES ESCOLARES?
}

\author{
CHOUKRI Ben AYED ${ }^{* *}$
}

\begin{abstract}
RESUMO: Este artigo dá conta do avanço dos conhecimentos sobre as desigualdades socioespaciais de acesso aos saberes na França. Embora este objeto envolva muitas questões societais, as pesquisas empíricas a ele consagradas continuam embrionárias. A que apresentamos aqui, muito abrangente, constitui um caso relativamente isolado. Depois de descrever a situação global das desigualdades na escolarização nesse país, o texto retoma a gênese da pesquisa. Insiste tanto no que está em jogo, metodologicamente, no estudo das variações do aprendizado escolar em função dos contextos de escolarização, quanto na necessidade de não dissociar, nas análises, o impacto dos fatores sociais e espaciais. De fato, hoje, uma das alavancas de renovação das abordagens na sociologia da educação consiste em levar em conta uma combinação dos dois.
\end{abstract}

Palavras-chaves: Desigualdades. Saberes. Currículo. Espaço. Território. Classes sociais.

\section{THE SOCIO-SPATIAL INEQUALITIES IN ACCESS TO KNOWLEDGE \\ A RENOVATION PROSPECT FOR THE SOCIOLOGY OF SCHOOLING INEQUALITIES?}

ABSTRACT: This paper scrutinizes the advancement of knowledge on socio-spatial inequalities in access to knowledge in France. Although this object encompasses many societal issues, empirical research devoted to it remains embryonic. The comprehensive one we present here is a relatively isolated case. After recalling the overall situation of schooling inequality in France, the text focuses on the research genesis. It particularly emphasizes the methodological stakes of studying the variations of educational attainment in different contexts of schooling and the need to avoid dissociating

\footnotetext{
* Tradução de Alain François, revista por Carolina Violante Peres.

** Sociólogo e professor da universidade de Limoges (França).E-mail: choukri.benayed@orange.fr
} 
the impact of social and spatial factors in our analyses. Taking a combination of both into account is now one of the levers that renew the approaches in sociology of education.

Key words: Inequalities. Knowledge. Curriculum. Space. Territory. Social classes.

\author{
LES INÉGALITÉS SOCIO-SPATIALES D'ACCÈS AUX SAVOIRS: \\ UNE PERSPECTIVE DE RENOUVELLEMENT DE LA SOCIOLOGIE DES \\ INÉGALITÉS SCOLAIRES?
}

\begin{abstract}
RÉSUMÉ: Cet article fait le point sur l'avancée des connaissances concernant les Inégalités socio-spatiales d'accès aux savoirs en France. Si cet objet recouvre de nombreux enjeux sociétaux, les recherches empiriques qui lui sont consacrées demeurent embryonnaires. Celle que nous présentons dans cet article, de grande ampleur, constitue un cas relativement isolé. Après avoir rappelé la situation globale des inégalités de scolarisation en France, l'article revient sur la genèse de cette recherche. Il insiste notamment sur l'enjeu méthodologique de l'étude des variations des acquisitions scolaires en fonction des contextes de scolarisation et sur la nécessité de ne pas dissocier dans l'analyse l'impact des facteurs sociaux et spatiaux. La prise en compte de ces deux facteurs combinés constitue aujourd'hui l'un des leviers de renouvellement des approches en sociologie de l'éducation.
\end{abstract}

Mots-clés: Inégalités. Savoirs. Curriculum. Espace. Territoire. Classes sociales.

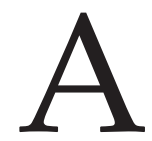

questão das desigualdades de escolarização conheceu, na França, evoluções marcantes no decorrer das três últimas décadas (Éducation et Société, 2000). As esperanças de democratização descortinadas pelo período de massificação não duraram muito. De fato, a ampliação das condições de acesso ao ensino médio favoreceu a emergência de novas formas de desigualdades perante a escola. A seleção social no ingresso ao sistema educativo foi substituída por outras formas de desigualdade mais difusas e contínuas ao longo da escolaridade. Estas se devem, em grande parte, à hierarquização das ofertas escolares e às estratégias familiares de matrículas escolares (évitements scolaires, ${ }^{1}$ escolha da escola), que reforçam e enrijecem as hierarquias iniciais (Ben Ayed \& Broccolichi, 2001; van Zanten, 2001; François \& Poupeau, 2008). Essa situação é semelhante à do Brasil, onde a forte estratificação do sistema educativo é também propícia ao desenvolvimento de estratégias familiares de escolarização (Ribeiro et al., 2010).

É nesse contexto que se deve situar a emergência de trabalhos consagrados à análise contextual das desigualdades de escolarização, os quais constituem um dos eixos de renovação das abordagens na sociologia da educação. Após uma breve descrição do estado das desigualdades escolares na França no período atual, retomaremos mais especificamente a pesquisa que temos desenvolvido sobre as desigualdades socioespaciais na educação. Insistiremos no que está em jogo, 
metodologicamente, nesse procedimento, em particular, na nossa preocupação em não dissociar o impacto das variáveis sociais e espaciais. Revisaremos, finalmente, os seus principais ensinamentos.

\section{As desigualdades de acesso aos saberes: a persistência dos deter- minismos culturais, econômicos e sociais.}

Quem se interessa pelas desigualdades da escolarização na França impressiona-se com a persistência de um conjunto de fatores e da profunda discrepância entre as intenções politicamente proclamadas e o que ocorre na realidade. De fato, o capítulo primeiro do Code de l'Éducation (Código da Educação) frisa que:

\footnotetext{
A escola garante a todos os alunos a aprendizagem e o domínio da língua francesa (...). O direito à educação é garantido a todos de modo que possam desenvolver a sua personalidade, elevar o seu nível de formação inicial e contínua, inserir-se na vida social e profissional, exercer a sua cidadania (...). A aprendizagem de uma cultura geral e de uma qualificação reconhecida é garantida a todos os jovens, quaisquer que sejam suas origens social, cultural ou geográfica.
}

Apesar dessas declarações, só podemos constatar que as reformas que se sucederam desde o fim da Segunda Guerra Mundial não conseguiram erradicar o vínculo particularmente forte entre origem social e desigualdades de escolarização. De fato, as tentativas de unificação (supressão da dupla rede de ensino [primário profissionalizante para os filhos do povo e primário destinado à continuação dos estudos para os filhos da burguesia] e abolição das diferenciações de percurso) redundaram num fracasso.

Obviamente, a criação de um ensino fundamental II único e a abertura do ensino médio e universitário a um maior número de alunos permitiram um aumento muito significativo da proporção de diplomados numa geração e das taxas de escolarização (Maurin, 2007). Contudo, essas considerações demográficas ocultam desigualdades ainda muito maciças. Como mostra o quadro 1 , a seguir, a partir do ingresso no ensino médio, as trajetórias dos alunos são muito diferentes segundo o nível cultural do pai. Mais da metade dos alunos cujos pais não se formaram ou têm apenas um Certificat d'Études Primaires (CEP - Diploma de fim do fundamental I) repetiu pelo menos um ano no fundamental I, ao passo que, quando o pai é titular de um diploma de nível $b a c+2,{ }^{2}$ este número é inferior a $25 \%$. Sabendo-se que os atrasos escolares acumulados desde o início da escolaridade comprometam muitíssimo as oportunidades de continuar os estudos (Oeuvrard, 2000), esse primeiro quadro salienta a persistência de uma reprodução cultural particularmente precoce, na escola. 


\section{Quadro 1}

Atraso no ingresso na $5^{\text {a }}$ série em função do diploma do pai

\begin{tabular}{|l|c|c|c|}
\hline & Atrasados & Atraso de 1 ano & Atraso de 2 anos ou mais \\
\hline Nenhum diploma ou CEP & $54 \%$ & $43,5 \%$ & $10,5 \%$ \\
\hline CAP, BEP, BEPC 3 & $36,5 \%$ & $31 \%$ & $5,6 \%$ \\
\hline Baccalauréat & $22,4 \%$ & $19,3 \%$ & $3,1 \%$ \\
\hline Bac + 2 ou mais & $14,1 \%$ & $12,1 \%$ & $2 \%$ \\
\hline
\end{tabular}

Fonte: Insee, Enquête emploi (Pesquisa Emprego, 2002).

Essas discrepâncias nas taxas de atraso no ingresso na quinta série estão vinculadas a diferenças de aprendizagem escolar, também bastante marcadas. Isto pode ser verificado no quadro 2, baseado em processamentos realizados por Sylvain Broccolichi e Rémi Sinthon a partir dos dados do Painel 1995 da Educação Nacional sobre uma amostra representativa do total dos alunos franceses (Broccolichi \& Sinthon, 2011). Esses pesquisadores elaboraram um indicador sintético do capital escolar familiar ao somar o nível cultural do pai e da mãe. Este indicador explica muito bem o nível de aprendizagem dos alunos na avaliação nacional realizada no ingresso na $5^{\text {a }}$ série, a qual mede o nível de domínio dos saberes fundamentais adquiridos durante o fundamental I. Ora, 34 \% dos alunos cujos pais têm um baixo capital escolar não ultrapassam o quintil 1 em matemática e francês, ao passo que essa proporção é apenas de $5 \%$ para os alunos cujos pais têm um alto capital escolar (baccalauréat ou mais).

\section{Quadro 2}

Resultados na avaliação nacional de $5^{\mathrm{a}}$ série (média para matemática e francês), segundo o capital escolar familiar (Painel 1995)

\begin{tabular}{|l|c|c|}
\hline & Quintil 1 & Quintil 5 \\
\hline Conjunto do Painel & $20 \%$ & $20 \%$ \\
\hline Pais com baixo capital escolar & $34 \%$ & $9 \%$ \\
\hline Pais com alto capital escolar & $5 \%$ & $42 \%$ \\
\hline
\end{tabular}

Fonte: Painel 1995 da Educação Nacional (apud Broccolichi \& Sinthon, 2011).

Como era de se esperar, a acumulação das taxas de atrasos e dos déficits de aprendizagem redundou em desigualdades nos diplomas escolares. Apenas 10\% dos filhos de operários não qualificados ou de inativos, contra $62 \%$ dos filhos de docentes e 52\% dos filhos de executivos superiores obtêm um diploma de nível igual ou superior a $b a c+3$, após o ensino médio. Em compensação, 58\% dos filhos de operários não qualificados ou de inativos saem do ensino médio com um diploma inferior ao baccalauréat ou sem diploma, contra apenas $12 \%$ dos filhos de docentes. 


\section{Quadro 3}

Nível de diploma alcançado pelos alunos segundo a profissão do pai (Painel 1995).

\begin{tabular}{|l|c|c|}
\hline & $\begin{array}{c}\text { Diplomas inferiores ao baccalauréat } \\
\text { ou nenhum diploma }\end{array}$ & $\begin{array}{c}\text { Diplomas de nível igual } \\
\text { ou superior a bac +3 }\end{array}$ \\
\hline Docentes & $12 \%$ & $62 \%$ \\
\hline Executivos superiores & $15 \%$ & $52 \%$ \\
\hline Funcionários & $43 \%$ & $19 \%$ \\
\hline $\begin{array}{l}\text { Operários não qualificados } \\
\text { inativos }\end{array}$ & $58 \%$ & $10 \%$ \\
\hline
\end{tabular}

Fonte: Senado, Relatório de informação n. 370, de 3 de junho de 2008.

Esse vínculo tênue entre níveis de aprendizagem escolar e origem social dos alunos foi recentemente confirmado pelos dados do Pisa 2009. Essa pesquisa mostra que o peso da variância dos desempenhos dos alunos ligada à origem social é de 17\% na França e que está aumentando regularmente há uma década (Meuret \& Lambert, 2011). Em comparação, é de $8 \%$ e 9\%, respectivamente, na Finlândia e no Canadá (OCDE, 2010). Essa realidade das desigualdades de escolarização também foi o objeto de um relatório do Conseil Économique et Social Environnemental (Cese Conselho Econômico e Social Ambiental), em setembro de 2011, que enfatiza, em particular, os elementos seguintes:

As desigualdades no êxito dos alunos estão muito claramente vinculadas às desigualdades sociais e culturais das suas famílias. Ora, a escola não consegue mais diminuir essas desigualdades originárias, as quais tendem inclusive, hoje, a aumentar ao longo da escolaridade (...). Nosso sistema educativo deixou, portanto, de ser um fator de redução das desigualdades (...). 20\% dos alunos de 15 anos obtiveram, em 2009, no teste internacional Pisa, resultados inferiores ao nível que os peritos consideram como o mínimo requerido para conservar todas as suas chances de êxito na vida adulta. Essa proporção de alunos com sérios problemas de aprendizagem escolar, no fim do fundamental II, aumentou em 30\% no decorrer dos dez últimos anos. (Cese, 2011)

\section{As desigualdades socioespaciais da educação na França: a face oculta das desigualdades de escolarização}

Como acabamos de ver, o sistema educativo francês está produzindo desigualdades sociais e culturais sempre muito marcadas perante a escola. Vamos mostrar que estas também têm uma natureza espacial. $O$ fato de essa característica ser menos conhecida não impede que seja igualmente determinante. Embora este objeto envolva questões societais importantes e uma forte demanda social, as pesquisas empíricas a ele consagradas continuam embrionárias. A que apresentamos aqui, 
muito abrangente, constitui um caso relativamente isolado (Ben Ayed, Broccolichi \& Trancart, 2006, 2010; Ben Ayed \& Broccolichi, 1998, 2009). Foi realizada no âmbito de uma encomenda institucional inusitada, pois partia de três instituições que costumam trabalhar separadamente: o Ministère de l'Éducation Nationale (Ministério da Educação Nacional), o Ministère de la Recherche (Ministério da Pesquisa) e a Délégation à l'Aménagement du Territoire et à l'Action Régionale (Datar - Delegação para o Desenvolvimento Territorial e a Ação Regional).

As preocupações dessas instituições diziam respeito às transformações da escola sob uma perspectiva político-administrativa: declínio das regulações do Estado, descentralização, desconcentração, territorialização da ação educativa, autonomia dos estabelecimentos escolares. A questão em aberto concernia ao impacto dessas transformações nas disparidades territoriais de educação. Essa encomenda pública de pesquisa deve ser relacionada às lógicas de fragmentação escolar e de aumento dos processos segregadores evidenciadas por um conjunto de pesquisas (Ben Ayed \& Broccolichi, 2001; Ben Ayed, 2009a; Broccolichi, 1998; van Zanten, 2001; Payet, 1995; Thin, 1998). Entretanto, o seu caráter essencialmente microssociológico dificultava a apreensão dos vínculos entre os mecanismos complexos de diferenciação da oferta educativa em escala local e a estrutura mais geral das desigualdades de escolarização. Essa perspectiva exigia a implementação de um dispositivo de pesquisa que articulasse as abordagens micro e macrossociológica. O edital de projetos incitava esse tipo de análise assim como uma ultrapassagem da escala do estabelecimento escolar, para que a pesquisa não se confundisse com a problemática da escola eficiente. Também estimulava a explorar escalas geográficas não necessariamente coincidentes com os recortes administrativos da educação nacional. Portanto, a ideia de variações geográficas das desigualdades escolares estava mesmo no cerne do projeto de pesquisa.

Uma das dificuldades enfrentadas na sua implementação foi a ausência de dados científicos anteriores. Tínhamos acesso apenas a elementos factuais da Direction de l'Évaluation et de la Prospective du Ministère de l'Éducation Nationale (Direção da Avaliação e da Prospectiva do Ministério da Educação Nacional), publicados na revista Géographie de l'École (Geografia da Escola), a respeito da repartição dos alunos no território, das proporções de diplomados, da alocação das despesas na educação, ou das taxas de êxito em diferentes níveis do currículo escolar. Esses dados logo se revelariam inadaptados à problematização da nossa pesquisa.

\section{A construção de um dispositivo de pesquisa}

O dispositivo de pesquisa que implementamos reuniu 17 pesquisadores de diversas disciplinas (Sociologia, História, Demografia, Estatística, Didática) que trabalham em oito laboratórios diferentes. A pesquisa foi realizada de 2002 a 2006 com 
fases de atualização até 2011 (Ben Ayed, 2011; Broccolichi \& Sinthon, 2011). Em termos de objetivos, visava apreender as variações espaciais das aprendizagens escolares em diferentes escalas geográficas e institucionais, levando em conta a composição social dos públicos e as formas específicas de variações dessas aprendizagens entre grupos sociais. Foi estruturada em torno de hipóteses oriundas das nossas investigações anteriores, que mostravam vínculos estreitos entre processos segregadores, perturbação das condições de escolarização e desigualdades de acesso aos saberes. Centrou-se essencialmente no ingresso e na saída do fundamental II em escala departamental, o que nos permitiu discernir variações de aprendizagem escolares mais fortes. O fundamental II é um dos segmentos mais sensíveis do sistema educativo francês, e dispomos, a seu respeito, dos dados mais confiáveis para medir as variações de aprendizagens dos currículos escolares com a ajuda das avaliações padronizadas no ingresso na quinta série e dos dados oriundos do diploma nacional chamado Brevet des Collèges (diploma de conclusão do fundamental II).

As variações locais nas aprendizagens escolares foram discernidas a partir de retas de regressão, levando em conta o nível de êxito médio dos alunos em escala nacional segundo a sua categoria social e os resultados esperados em função do índice de precariedade social calculado para cada escola (Figura 1). Os estabelecimentos foram classificados em sobre-êxito, quando o resultado observado era superior ao esperado, e em sob-êxito, quando era inferior. Esses resultados foram em seguida somados em escala departamental. O cálculo da média das diferenças entre os resultados observados e esperados em função do índice de precariedade permitiu classificar os departamentos em sobre ou sob-êxito escolar (Quadros 4 e 5).

\section{Cálculo do índice de precariedade segundo Danièle Trancart}

O índice de precariedade leva em conta, para cada escola francesa, a porção de alunos de $5^{a}$ série oriundos das categorias operário, inativo, muito favorecido (executivos, profissões intelectuais superiores, empresários com mais de dez assalariados, docentes), bolsistas, proporção de alunos estrangeiros.

O índice de precariedade global foi elaborado assim: para cada escola e cada uma das cinco variáveis acima calculou-se o Z-score, subtraindo a média do valor inicial de uma escola e dividindo o resultado pelo desvio padrão. Em seguida, determinou-se a soma algébrica dos desvios obtidos. Este índice é nulo, na média; positivo, se o contexto social da escola for "desfavorecido"; e negativo no caso contrário (para mais detalhes, ver o relatório final em Ben Ayed, Broccolichi \& Trancart, 2006).

A partir desse modelo estatístico de previsão dos desempenhos escolares, que leva em conta a composição social dos públicos, pudemos extrair os doze departamentos mais em sob-êxito escolar e os doze departamentos mais em sobre-êxito escolar. $^{4}$ 
As desigualdades socioespaciais de acesso aos saberes...

\section{Quadro 4}

Os doze departamentos em que os resultados na avaliação da $5^{\text {a }}$ série foram os mais inferiores aos resultados esperados em 2001-2002.

\begin{tabular}{|c|c|c|c|c|c|c|c|c|c|c|c|c|}
\hline \multirow{2}{*}{ Departamentos } & \multirow{2}{*}{$\begin{array}{c}\mathbf{N}^{\circ} \\
\text { de } \\
\text { colé- } \\
\text { gios }\end{array}$} & \multicolumn{3}{|c|}{$\begin{array}{c}\text { Média } \\
\text { Avaliação } 5^{\mathrm{a}} \text { série }\end{array}$} & \multicolumn{3}{|c|}{ Avaliação $5^{a}$ série } & \multirow{2}{*}{$\begin{array}{c}\text { Índ. } \\
\text { preca- } \\
\text { riedade }\end{array}$} & \multirow{2}{*}{$\begin{array}{c}\% \text { rural } \\
\text { ou } \\
\text { isolado }\end{array}$} & \multicolumn{3}{|c|}{$\begin{array}{l}\text { Índice de } \\
\text { precariedade }\end{array}$} \\
\hline & & $\begin{array}{c}\text { Obser- } \\
\text { vado }\end{array}$ & $\begin{array}{l}\text { Espe- } \\
\text { rado }\end{array}$ & Desvio & $\begin{array}{c}\text { Decil } \\
1\end{array}$ & $\begin{array}{c}\text { Decil } \\
9\end{array}$ & $\begin{array}{l}\text { d9- } \\
\text { d1 }\end{array}$ & & & $\begin{array}{c}\text { Decil } \\
1\end{array}$ & $\begin{array}{c}\text { Decil } \\
9\end{array}$ & $\begin{array}{l}\text { D9- } \\
\text { D1 }\end{array}$ \\
\hline Oise & 65 & 63,5 & 68,7 & $-5,1$ & 57,8 & 69,0 & 11,3 & 0,3 & $37 \%$ & $-2,8$ & 4,7 & 7,6 \\
\hline Val d'Oise & 98 & 65,3 & 70,2 & $-5,0$ & 55,9 & 72,9 & 17,0 & $-0,7$ & $2 \%$ & $-6,3$ & 5,2 & 11,5 \\
\hline Seine St Denis & 91 & 59,6 & 64,2 & $-4,7$ & 52,5 & 67,5 & 15,1 & 3,3 & $0 \%$ & $-1,9$ & 7,9 & 9,8 \\
\hline Essonne & 93 & 68,5 & 72,6 & $-4,2$ & 60,5 & 76,0 & 15,5 & $-2,3$ & $4 \%$ & $-6,9$ & 3,4 & 10,3 \\
\hline Seine et Marne & 118 & 67,4 & 71,5 & $-4,1$ & 62,1 & 72,6 & 10,5 & $-1,5$ & $24 \%$ & $-5,3$ & 2,1 & 7,4 \\
\hline Yvelines & 111 & 70,5 & 74,3 & $-3,8$ & 59,5 & 78,0 & 18,6 & $-3,4$ & $8 \%$ & $-8,8$ & 4,2 & 13,0 \\
\hline Eure & 56 & 65,2 & 68,7 & $-3,5$ & 61,2 & 70,5 & 9,3 & 0,3 & $23 \%$ & $-3,0$ & 2,5 & 5,5 \\
\hline Somme & 50 & 62,5 & 66,0 & $-3,5$ & 55,3 & 67,9 & 12,6 & 2,1 & $42 \%$ & $-1,0$ & 4,1 & 5,2 \\
\hline Val de Marne & 100 & 67,0 & 70,4 & $-3,4$ & 59,5 & 75,2 & 15,6 & $-0,8$ & $0 \%$ & $-6,5$ & 4,1 & 10,6 \\
\hline Alpes maritimes & 67 & 66,8 & 70,0 & $-3,2$ & 62,1 & 72,4 & 10,3 & $-0,6$ & $13 \%$ & $-4,8$ & 4,7 & 9,5 \\
\hline Eure et Loire & 41 & 66,1 & 69,3 & $-3,2$ & 60,4 & 71,5 & 11,1 & $-0,1$ & $27 \%$ & $-4,1$ & 4,5 & 8,6 \\
\hline Hauts de Seine & 91 & 69,6 & 72,5 & $-2,9$ & 60,1 & 78,0 & 17,9 & $-2,3$ & $0 \%$ & $-8,1$ & 3,7 & 11,8 \\
\hline Média & 82 & 66,3 & 70,3 & -4 & 58,9 & 73,2 & 14,3 & $-0,7$ & $12 \%$ & $-5,4$ & 4,2 & 9,7 \\
\hline
\end{tabular}

Fonte: Processamentos realizados por Danièle Trancart e Sylvain Broccolichi para a pesquisa "As desigualdades socioespaciais na educação. Capital social e políticas territoriais" (Ben Ayed, Broccolichi \& Trancart, 2006).

\section{Quadro 5}

Os doze departamentos em que os resultados na avaliação $5^{\mathrm{a}}$ série foram os mais superiores aos resultados esperados em 2001-2002.

\begin{tabular}{|c|c|c|c|c|c|c|c|c|c|c|c|c|}
\hline \multirow{2}{*}{ Departamentos } & \multirow{2}{*}{$\begin{array}{l}N^{o} \text { de } \\
\text { Colé- } \\
\text { gios }\end{array}$} & \multicolumn{3}{|c|}{$\begin{array}{c}\text { Média } \\
\text { avaliação } 5^{\mathrm{a}} \text { série }\end{array}$} & \multicolumn{3}{|c|}{ Avaliação $5^{\mathrm{a}}$ série } & \multirow{2}{*}{$\begin{array}{c}\text { Índ. } \\
\text { preca- } \\
\text { riedade }\end{array}$} & \multirow{2}{*}{$\begin{array}{c}\% \\
\text { rural } \\
\text { ou } \\
\text { isolado }\end{array}$} & \multicolumn{3}{|c|}{$\begin{array}{c}\text { Índice de } \\
\text { precariedade }\end{array}$} \\
\hline & & \begin{tabular}{|l|} 
Obser- \\
vado
\end{tabular} & $\begin{array}{l}\text { Espe- } \\
\text { rado }\end{array}$ & Desvio & $\begin{array}{c}\text { Decil } \\
1\end{array}$ & $\begin{array}{c}\text { Decil } \\
9\end{array}$ & $\begin{array}{l}\text { d9- } \\
\text { d1 }\end{array}$ & & & $\begin{array}{c}\text { Decil } \\
1\end{array}$ & $\begin{array}{c}\text { Decil } \\
9\end{array}$ & $\begin{array}{l}\text { D9- } \\
\text { D1 }\end{array}$ \\
\hline Cantal & 23 & 72,1 & 69,9 & $+2,2$ & 67,5 & 76,6 & 9,1 & $-0,5$ & $74 \%$ & $-1,9$ & 1,0 & 2,9 \\
\hline Allier & 37 & 71,1 & 68,8 & $+2,3$ & 65,4 & 76,5 & 11,1 & 0,2 & $49 \%$ & $-2,0$ & 2,0 & 4,0 \\
\hline Hautes Pyrénées & 20 & 73,8 & 71,3 & $+2,5$ & 69,8 & 77,2 & 7,5 & $-1,4$ & $45 \%$ & $-3,4$ & 1,0 & 4,4 \\
\hline Mayenne & 27 & 71,9 & 69,3 & $+2,6$ & 68,6 & 75,7 & 7,1 & $-0,1$ & $63 \%$ & $-2,5$ & 1,8 & 4,3 \\
\hline Côte d'or & 47 & 72,7 & 70,1 & $+2,6$ & 68,4 & 78,7 & 10,3 & $-0,6$ & $45 \%$ & $-4,0$ & 2,2 & 6,2 \\
\hline Meuse & 24 & 70,0 & 67,3 & $+2,7$ & 64,9 & 73,0 & 8,1 & 1,2 & $50 \%$ & $-0,5$ & 3,0 & 3,5 \\
\hline Lot et Garonne & 28 & 70,9 & 68,1 & $+2,7$ & 67,4 & 74,3 & 7,0 & 0,7 & $32 \%$ & $-1,9$ & 2,9 & 4,8 \\
\hline Vendée & 29 & 71,8 & 69,0 & $+2,9$ & 66,4 & 76,1 & 9,7 & 0,1 & $72 \%$ & $-1,9$ & 2,4 & 4,3 \\
\hline Landes & 32 & 74,0 & 71,0 & $+3,0$ & 70,0 & 77,2 & 7,2 & $-1,3$ & $59 \%$ & $-2,7$ & 0,1 & 2,8 \\
\hline $\begin{array}{l}\text { Pyrénées } \\
\text { atlantiques }\end{array}$ & 48 & 74,2 & 71,0 & $+3,2$ & 70,1 & 78,4 & 8,4 & $-1,3$ & $38 \%$ & $-3,6$ & 0,7 & 4,3 \\
\hline Loire & 51 & 71,1 & 67,7 & $+3,4$ & 66,6 & 76,9 & 10,3 & 1,0 & $24 \%$ & $-2,7$ & 6,9 & 9,5 \\
\hline Haute Loire & 21 & 73,3 & 69,7 & $+3,6$ & 68,0 & 77,5 & 9,5 & $-0,3$ & $71 \%$ & $-1,5$ & 0,8 & 2,4 \\
\hline Média & 32 & 72,3 & 69,4 & 2,9 & 67,8 & 76,7 & 9,0 & $-0,2$ & $49 \%$ & $-2,6$ & 2,3 & 4,9 \\
\hline
\end{tabular}

Fonte: Processamentos realizados por Danièle Trancart e Sylvain Broccolichi para a pesquisa "As desigualdades socioespaciais na educação. Capital social e políticas territoriais" (Ben Ayed, Broccolichi \& Trancart, 2006). 


\section{Caixa 1}

Leitura dos quadros 4 e 5

Essas duas tabelas mostram, para os 24 departamentos franceses mais em sobre e sob-êxito, os resultados observados e esperados na avaliação da $5^{a}$ série. Os sobre ou sob-êxitos foram calculados com a ajuda de modelos de regressão simples: o resultado esperado na avaliação da $5^{\text {a }}$ série corresponde ao valor predito em função do índice de precariedade. O desvio entre o resultado observado e o resultado esperado representa um sobre-êxito quando o desvio é positivo, ou um sob-êxito, no caso contrário. Esses cálculos foram realizados para cada escola francesa e, em seguida, reunidos em nível departamental.

Em cada tabela, um indicador de disparidades no recrutamento escolar das escolas do departamento foi calculado, levando em conta os primeiros e nonos decis (valores máximos e mínimos dos resultados dos 10\% de escolas mais "fracas" e dos $10 \%$ mais "fortes"), e em seguida a diferença interdecil (D9-D1). Uma diferença elevada, como em Yvelines (18,6), traduz a importância das disparidades de nível escolar dos alunos no ingresso na $5^{\text {a }}$ série, segundo as escolas. As colunas seguintes indicam o índice de precariedade departamental, os decis e a diferença interdecil (D9-D1) do índice de precariedade, assim como um índice de densidade urbana, calculado a partir da proporção de escolas localizadas em área dita rural ou isolada (categoria Insee da unidade urbana à qual a escola está vinculada).

A distinção entre esses dois grupos de departamentos com perfis muito opostos favoreceu as comparações em termos tanto estatísticos quanto qualitativos. No plano estatístico, a análise foi enriquecida por variáveis suplementares: indicador de densidade urbana (porcentagem de rural/isolado), diferenças interdecis na avaliação da $5^{a}$ série (diferenças de êxito entre escolas de um mesmo departamento) e diferenças interdecis do índice de precariedade (indicador de segregação e concentração de alunos oriundos de meios populares por estabelecimento em cada departamento). No plano qualitativo, uma amostra de cinco dos departamentos heterogêneos foi objeto de estudos monográficos aprofundados: Yvelines, Seine-Saint-Denis, LoireAtlantique, Hérault, Loire. Essas monografias consistiram numa série de observações e de entrevistas com os pessoais escolares, responsáveis administrativos, eleitos locais, responsáveis associativos e, em alguns casos, alunos. Também reconstituíram a história social dos lugares escolhidos e processaram um conjunto de dados estatísticos locais geralmente mais precisos que os disponíveis em nível nacional.

\section{Quais características discriminam departamentos opostos?}

A construção da tipologia dos dois grupos de departamentos opostos forneceu um conjunto de informações e surpresas. Primeiro, a pertinência da variável departamental demonstra que a repartição entre sobre e sob-êxito é parcialmente independente dos recortes administrativos oficiais. Os três departamentos mais em 
sob-êxito (Oise, Val-d'Oise e Seine-Saint-Denis) e os dois departamentos mais em sobre-êxito (Haute-Loire e Loire) pertencem a cinco académies $^{5}$ diferentes (Amiens, Versailles, Créteil, Clermont-Ferrand e Lyon). Assim, ao que tudo indica, os sobre e sob-êxitos explicam-se muito mais por caracteres morfológicos (características sociais e demográficas locais) do que pelo impacto das políticas educacionais que vigoram nesses territórios. Essa intuição é fundamentada mais ainda pelo fato de a maioria dos departamentos em sobre e sob-êxito estarem quase sempre próximos geograficamente, em particular os em sob-êxito, que são concentrados, principalmente, na região Ille-de-France. ${ }^{6}$

Para compreender o sentido dessa distribuição não aleatória das hierarquias departamentais, é preciso entender os seus traços morfológicos finos, como os ressaltados pelas Tabelas 4 e 5 e por pesquisas de campo. Os departamentos mais em sob-êxito caracterizam-se primeiro por uma forte densidade tanto de população, quanto de estabelecimentos escolares (quatro vezes mais alta que na de grupo oposto). Também apresentam disparidades mais marcadas entre escolas, tanto em termos de diferenças sociais de recrutamento, quanto de desempenho escolar. Essas duas propriedades morfológicas condicionam as lógicas de concorrência unilateral entre estabelecimentos, as práticas de évitement scolaire e a seleção das candidaturas nos estabelecimentos mais procurados. Essas constatações são coerentes com as pesquisas de campo consagradas ao évitement scolaire em meio urbano (Broccolichi, 1998; van Zanten, 2001; Oberti, 2007) e com as monografias sobre cada local.

Como mostra a Figura 2 (mais adiante), essas propriedades específicas dos departamentos em sob-êxito condicionam fortemente as chances de êxito ulterior no Brevet des Collèges para todos os grupos sociais, não apenas os oriundos de meios populares. Essas desigualdades se aprofundam particularmente no grupo de departamentos mais em sob-êxito, uma vez que, neles, todas as diferenças de resultados entre grupos sociais são mais marcadas (sendo que todos os resultados já são mais baixos). Contudo, é preciso notar que a diferença de resultados é maior entre os filhos de executivos e os do grupo dos profissionais de nível intermediário. Esse resultado mostra claramente que não podemos atribuir as perturbações geradoras de déficits de aprendizagem em meio urbano unicamente aos efeitos do processo de guetização dos estabelecimentos, uma vez que afetam essencialmente as populações mais deserdadas e mais dependentes desses estabelecimentos.

Essas constatações, que discrepam das nossas intuições iniciais, mostram que o sob-êxito não se limita apenas ao caso das "escolas-guetos", mas aflige territórios muito mais amplos. Os sob-êxitos também não resultam apenas da concentração de alunos oriundos dos meios populares nos territórios. Alguns departamentos em sob-êxito (como Yvelines) estão, de fato, entre os mais "ricos" da França. Em compensação, é neles que se observam as disparidades mais fortes tanto em termo de 


\section{Figura 1}

Nuvens de pontos das escolas públicas nos cinco departamentos salientados, em função do seu índice de precariedade e dos seus resultados na avaliação da $5^{\mathrm{a}}$ série.
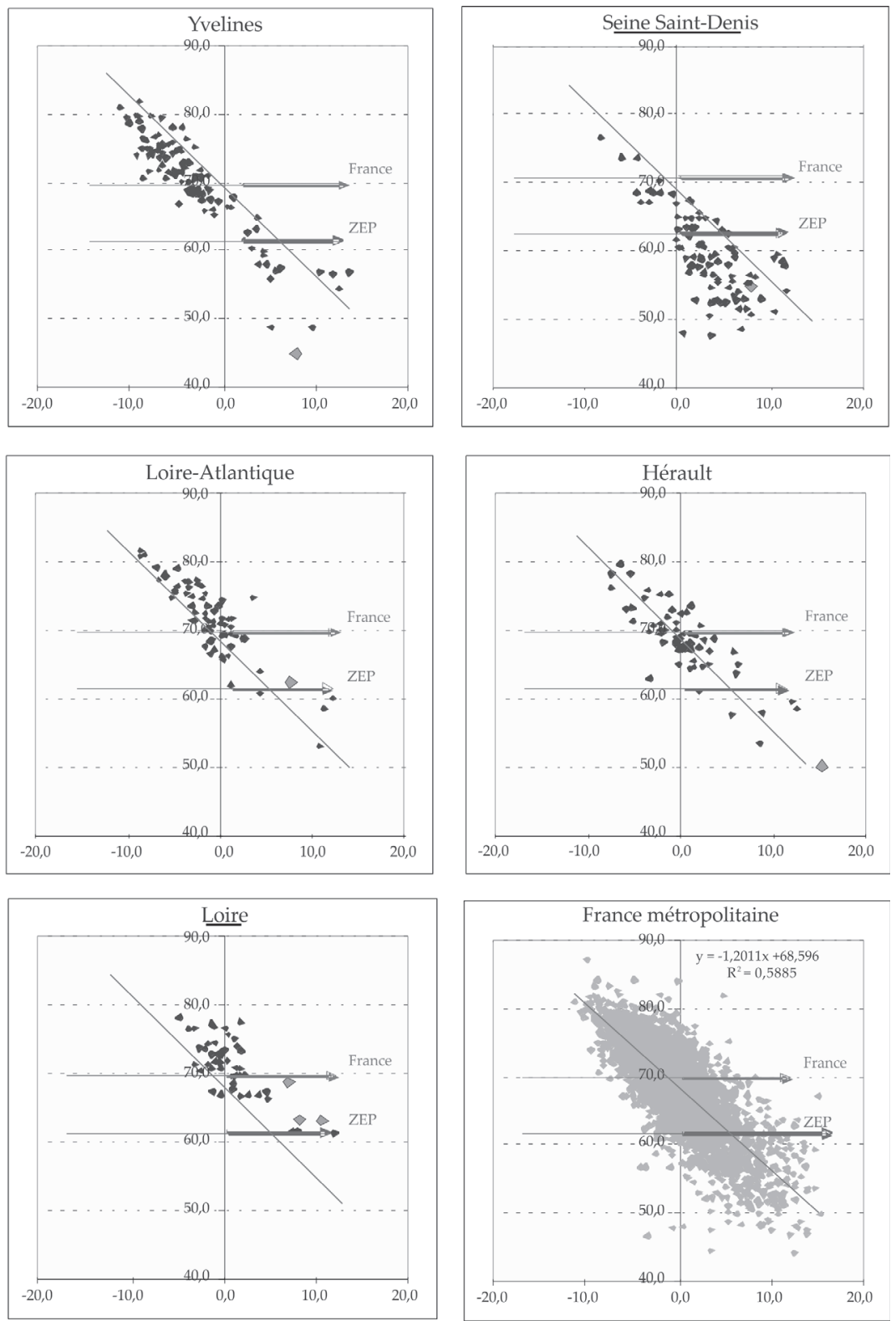

Fontes: Processamentos realizados por Danièle Trancart e Sylvain Broccolichi para a pesquisa "As desigualdades socioespaciais na educação. Capital social e políticas territoriais" (Ben Ayed, Broccolichi \& Trancart, 2006) - Cada quadrado representa uma escola. Os quadrados maiores correspondem às que foram objeto de pesquisas aprofundadas. 
Sobre- e sub-êxito dos departamentos na avaliação da $5^{\mathrm{a}}$ série (mais- ou menos-valia em função da estrutura social dos alunos escolarizados em $5^{\mathrm{a}}$ série no ano letivo 2001-2002)

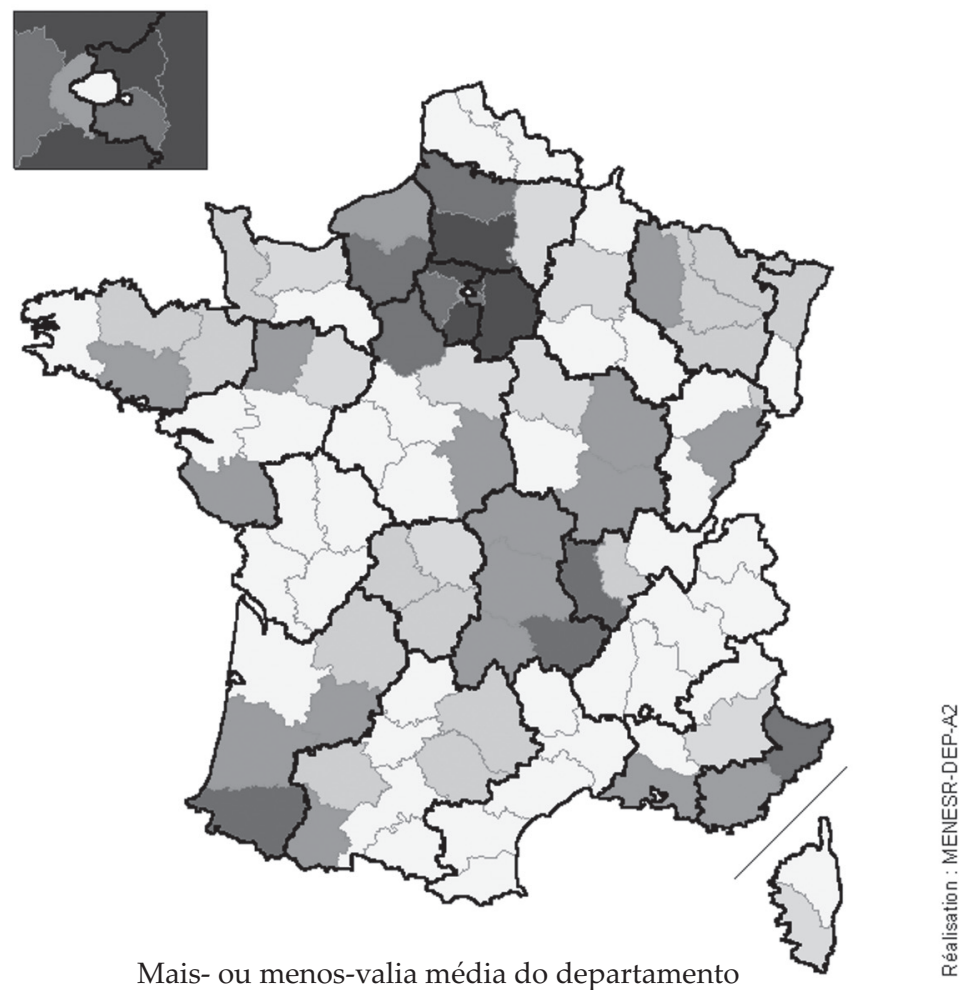

Mais- ou menos-valia média do departamento

$$
\begin{aligned}
& +3 \text { e mais } \\
& +2 \mathrm{a}+2,9 \\
& +1 \mathrm{a}+1,9 \\
& \square-1 \mathrm{a}+0,9 \\
& -2 \mathrm{a}-1,1 \\
& -3 \mathrm{a}-2,1 \\
& -4 \mathrm{a}-3,1 \\
& \text { inferior } \mathrm{a}-4
\end{aligned}
$$

recrutamento dos estabelecimentos, quanto de desempenho escolar. Em outras palavras, as lógicas de concorrência, de segregação e de desigualdade discernidas nesses locais "puxam" as suas médias para baixo. Ou seja, os poucos estabelecimentos de elite que emergem das lógicas de concorrência não conseguem inverter as médias globalmente fracas vinculadas à concentração excessiva de alunos em dificuldade nos mesmos estabelecimentos escolares. Os sob-êxitos não são automaticamente relacionados à concentração dos alunos de meios populares, pois certos departamentos entre os mais populares (como o da Loire, ao qual voltaremos) estão também entre os que têm mais sobre-êxito. 


\section{Figura 2}

Desigualdades no êxito escolar segundo os grupos de departamentos e a origem social (média para Matemática e Francês nas provas do Brevet des Collèges, em 2004).

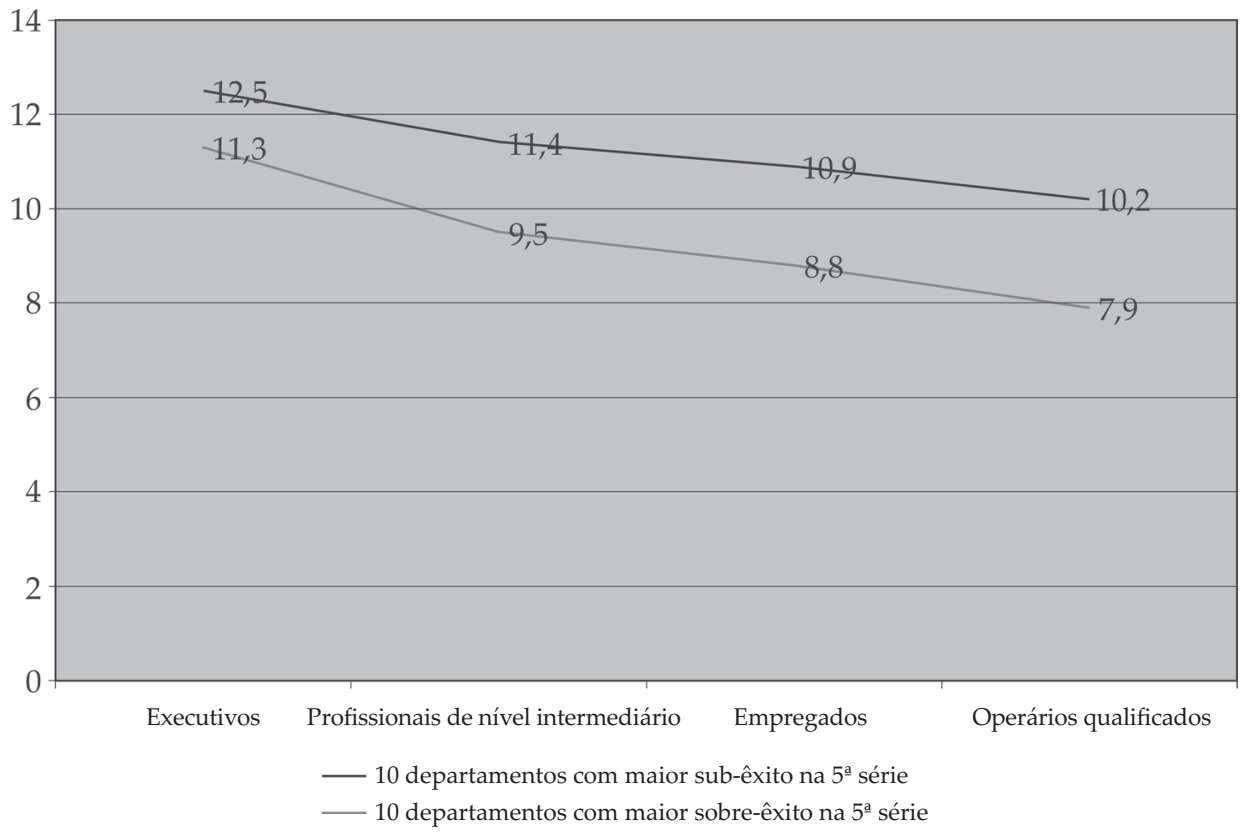

Fonte: Processamentos realizados por Broccolichi a partir dos dados nacionais do DNB (2003-2004) para a pesquisa "As desigualdades socioespaciais na educação. Capital social e políticas territoriais" (Ben Ayed, Broccolichi \& Trancart, 2006).

\section{Confiança ou concorrência? Dois esquemas explicativos das variações locais nos desempenhos escolares}

As pesquisas de campo salientaram traços distintivos nítidos entre os territórios em sob e sobre-êxito. A oposição entre concorrência, por um lado, e confiança e cooperação durável, por outro, revelou-se particularmente marcada. Os territórios em sob-êxito são os que mais deixaram lógicas de évitement scolaire se desenvolverem, ao passo que os territórios em sobre-êxito, pelo contrário, implementaram modos de regulação das migrações escolares. Enquanto nos territórios em sob-êxito os estabelecimentos situados em área prioritária são encravados e frequentemente estigmatizados, nos territórios em sobre-êxito, estão muito mais em continuidade urbana e muito menos segregados. Do mesmo modo, nestes últimos observamos muito mais parcerias entre as escolas e o seu entorno urbano do que nos territórios em sob-êxito, marcados por uma descontinuidade entre as esferas educativa e local. Também notamos que os estabelecimentos mais em dificuldade situados nos territórios em sob-êxito estão 
isolados no plano institucional. Além do mais, concentram mais docentes novos, que sofrem um turn-over importante, o que angustia os profissionais e provoca tensões nas equipes educativas, sem falar do sentimento de abandono. ${ }^{7}$

\section{A Loire: uma exceção?}

Os déficits de aprendizagem constatados em meio urbano e os detalhes das suas variações em função dos meios sociais explicam-se por dois tipos de perturbações vinculadas à hierarquização dos espaços escolares. Por um lado, uma degradação muito visível das condições de escolarização nos estabelecimentos estigmatizados, nos quais são relegados os alunos que mais carecem de recursos. No lado oposto, existe uma elevação das exigências e uma seleção exacerbada que perturbam os percursos escolares dos alunos das classes populares e médias (e, em menor grau, também os de alunos oriundos das classes superiores).

Nesse esquema explicativo geral, o departamento da Loire, embora urbanizado, é uma exceção. Uma fração importante dos alunos oriundos de meios populares foge ao esquema habitual da desqualificação escolar em meio urbano. Como compreender essa exceção? Essa situação é tanto mais intrigante por se tratar de um departamento pauperizado. De fato, enquanto o índice de precariedade do conjunto das Réseaux d'Éducation Prioritaire (REPs - Redes de Educação Prioritária) francesas está em 5,2, o seu valor é respectivamente de 10,5, 8,1 e 6,9 para três das escolas mais características desse departamento. Nelas, a taxa de alunos desfavorecidos está, respectivamente, em $84,7 \%, 76,7 \%$ e $78,4 \%$, ao passo que a média nacional das REPs é de $65,4 \%$. Apesar dessa composição social, observa-se que os resultados médios nas avaliações na $5^{a}$ série são altos nessas três escolas: 63,2, 63,3 e 68,83, enquanto ficam em 61,3 no conjunto das REPs. Como interpretar esse sobre-êxito escolar, em particular em estabelecimentos incluídos em REPs?

\section{Quadro 6}

Devir dos alunos dois anos após a $8^{\underline{a}}$ série nas REPs e fora delas.

\begin{tabular}{|l|c|c|c|c|c|}
\hline & \multicolumn{3}{|c|}{ Acesso em $1^{\text {e }}$} & \multicolumn{2}{c|}{ Acesso em $1^{e}$ S } \\
\hline & Total & REP & Fora REP & REP & Fora REP \\
\hline França metropolitana & $31 \%$ & $21 \%$ & $33 \%$ & $10 \%$ & $17 \%$ \\
\hline Seine-Saint-Denis & $23 \%$ & $18,9 \%$ & $27,7 \%$ & $8,6 \%$ & $14 \%$ \\
\hline Académie de Lyon & $34 \%$ & $23,1 \%$ & $37 \%$ & $12,6 \%$ & $21 \%$ \\
\hline Loire & $33,6 \%$ & $31,7 \%$ & $34,2 \%$ & $16,9 \%$ & $19 \%$ \\
\hline Yvelines & $35,2 \%$ & $17,4 \%$ & $37,4 \%$ & $6,9 \%$ & $19,5 \%$ \\
\hline
\end{tabular}




\section{Quadro 7}

Especificidades do departamento da Loire na esfera escolar.

\begin{tabular}{|c|c|}
\hline $\begin{array}{l}\text { 1) População mais } \\
\text { desfavorecida }\end{array}$ & $\begin{array}{l}\text { Proporção de alunos de origem social desfavorecida: } 49,3 \% \\
\text { Média francesa: } 44,8 \% \\
\text { Académie de Lyon: } 43,20 \%\end{array}$ \\
\hline $\begin{array}{l}\text { 2) Segregação menos marcada } \\
\text { entre estabelecimentos }\end{array}$ & $\begin{array}{l}\text { Menor proporção de alunos desfavorecidos nas escolas } \\
22 \% \text { Loire } \\
\text { 7\% Bouches-du-Rhône } \\
8 \% \text { Rhône } \\
\text { 3\% Yvelines } \\
\text { Maior proporção de alunos favorecidos nas escolas } \\
\text { 30\% Loire } \\
\text { 56\% Bouches-du-Rhône } \\
\text { 70\% Rhône } \\
\text { 80\% Yvelines }\end{array}$ \\
\hline $\begin{array}{l}\text { 3) Menores diferenças de } \\
\text { êxito escolar entre alunos }\end{array}$ & $\begin{array}{l}\text { Diferença entre as maiores e menores notas } \\
\text { na avaliação da } 5^{\text {a }} \text { série } \\
28 \% \text { Loire } \\
74 \% \text { Bouches-du-Rhône } \\
59 \% \text { Rhône }\end{array}$ \\
\hline $\begin{array}{l}\text { 4) Percentagem de uma } \\
\text { geração no baccalauréat }\end{array}$ & $65 \%$ (Loire), 61,7\% (França inteira) e 61\% (Rhône) \\
\hline $\begin{array}{l}\text { 5) Pequeno tamanho dos } \\
\text { estabelecimentos escolares no } \\
\text { fundamental I e II }\end{array}$ & $\begin{array}{l}\text { Em 2003: } 13 \text { escolas públicas cujo tamanho médio é de } 532 \\
\text { alunos. } \\
\text { Em } 10 \text { anos, o ensino público perdeu } 22 \% \text { dos seus efetivos } \\
\text { e o ensino privado } 11 \% \text {. }\end{array}$ \\
\hline $\begin{array}{l}\text { 6) Escolarização das crianças } \\
\text { com } 2 \text { e } 3 \text { anos }\end{array}$ & 1999: 70\% (Loire) e 35\% (França) \\
\hline $\begin{array}{l}\text { 7) Estabilidade dos docentes: } \\
\text { fraca proporção de docentes } \\
\text { de menos de } 30 \text { anos }\end{array}$ & $\begin{array}{l}\text { Fundamental I: 10,5\% (Loire) e 12,6\% (França) } \\
\text { Fundamental II: 12,7\% (Loire) e 17\% (França) }\end{array}$ \\
\hline
\end{tabular}

A monografia sobre o departamento da Loire e, mais particularmente, a sua principal cidade, Saint-Étienne, ajuda a entender o que fez com que a espiral da desqualificação escolar fosse evitada e que os resultados escolares obtidos estivessem fora da norma. O estudo expõe dados estatísticos locais detalhados e apresenta uma pesquisa aprofundada em quatro escolas. Também entrevistamos responsáveis departamentais da educação nacional (inspetores escolares, inspetores escolares adjuntos), eleitos locais (deputado de circunscrição, vice-prefeito encarregado da política da cidade, senadora da Loire, ex-deputado, eleitos da oposição ao governo municipal), responsáveis das instituições locais (DDASS, CAF, ${ }^{9}$ juventude e 
esportes), os principais representantes associativos (grêmios laicos, associações de acompanhamento escolar e de educação popular) e responsáveis de estruturas especializadas que atendem a adolescentes. Todas essas informações levaram a focar a interpretação dos resultados da Loire em torno de três hipóteses: os efeitos da diversidade social, a mobilização educativa local em torno do aluno raro, a sobrevivência de solidariedades locais herdadas da sua história industrial. ${ }^{10}$

\section{Uma diversidade social banalizada}

Embora esteja vivendo, desde o começo dos anos de 1960, uma difícil reconversão, o departamento da Loire é particularmente marcado pela sua história industrial. Essa atividade foi propícia à chegada maciça de migrantes vindos da Itália, da Espanha, da Polônia, do Marrocos ou da Indochina. Isso contribuiu para a constituição de um proletariado urbano e de uma diversidade social na dinâmica local. Existem muitos indícios dessa diversidade social. Na cidade de Saint-Étienne, o centro não é verdadeiramente burguês e não existem estabelecimentos de elite capazes de instigar a hierarquização das ofertas escolares ou de ativar a alavanca do évitement scolaire. As ofertas escolares locais são percebidas como fracamente diferenciadas, tanto pelas famílias quanto pelos docentes. Num departamento em que a diversidade social é banalizada, o fato de pertencer às classes populares ou de ser oriundo da imigração não constitui um estigma, na medida em que essas propriedades não são exceções nem são percebidas negativamente pelos outros alunos ou pelo pessoal escolar.

\section{A mobilização educativa local em torno do "aluno raro"}

Os trabalhos que estudam as relações de interdependência entre os estabelecimentos escolares (Delvaux \& van Zanten, 2006; Maroy, 2006) mostram que as situações de depressão demográfica exacerbam as lógicas de competição entre estabelecimentos escolares, quer sejam de primeira ordem (em função do número de alunos matriculados), quer de segunda ordem (em função das suas qualidades sociais e escolares). Essas lógicas de concorrência estão na base dos processos segregadores. O departamento da Loire é particularmente marcado pelo seu declínio demográfico. Estima-se que, desde o fim dos anos de 1960, a cidade de SaintÉtienne perdeu 50 mil habitantes. Essa baixa demográfica afeta consideravelmente o espaço escolar e gera muitas dificuldades materiais, como a gestão de um parque escolar excendentário. Constitui também, numa certa medida, um trunfo, uma vez que favoreceu o desenvolvimento de uma política educativa em prol da escolaridade precoce, a partir dos dois anos. Entretanto, também, cria uma tensão, pois, com exceção das escolas localizadas nas áreas periféricas, a quase totalidade das 
escolas do departamento está ameaçada de fechamento. Por isso, tanto os docentes como os diretores de estabelecimentos estão apegados a cada aluno.

$\mathrm{O}$ fato de as lógicas de concorrência terem menos peso nesse departamento não se deve apenas à sua morfologia social e residencial, mas também a um "pacto de não agressão" firmado entre os diretores de estabelecimentos, sob a égide da inspeção escolar, em que estes se comprometem a não cobiçar os alunos de outros setores escolares e a instaurar, entre si, relações de cooperação. Este acordo desembocou na constituição de novos setores escolares favoráveis à diversidade social e a um relativo equilíbrio entre estabelecimentos.

\section{Solidariedades locais}

Embora os docentes, diretores de estabelecimentos e responsáveis administrativos entrevistados não tivessem consciência do sobre-êxito escolar do seu departamento (os dados locais brutos geralmente usados dificilmente permitiriam chegar a essa conclusão), custavam a atribuir esses resultados a uma política educativa específica. Em compensação, reconheceram agir para uma homogeneização das condições de escolarização em todos os estabelecimentos.

A explicação do sobre-êxito escolar no departamento da Loire deve-se provavelmente a fatores extraescolares, às interações entre a escola e seu entorno local. Os vínculos entre os pessoais escolares e os responsáveis associativos são particularmente fortes. O tecido associativo local é muito denso, o que concorre para uma forte continuidade educativa local: grêmios laicos, estruturas de acompanhamento escolar, políticas educacionais municipais. Pode-se pensar que esse tecido associativo permitiu evitar que certos bairros em dificuldades sejam deixados para trás. Também possibilitou estabelecer relações de confiança duráveis com as famílias e os alunos. De fato, essas associações costumam operar um acompanhamento envolvendo várias gerações de crianças oriundas da mesma família e podem se valer de um bom conhecimento do seu público. Nesse ponto, pudemos constatar que constituem uma mediação valiosa com a escola ou as municipalidades, em particular para estabelecer relações de cooperação em torno dos alunos em dificuldade.

\section{Conclusão e perspectivas}

As constatações que surgiram no decorrer desta pesquisa consagrada às desigualdades socioespaciais na educação tiveram prolongamentos de duas ordens. Os trabalhos de Sylvain Broccolichi e Rémi Sinthon vieram enriquecer a construção dos indicadores de segregação e concorrência escolar e ampliar as escalas de análise geográfica a grandes aglomerações francesas. Essa abordagem permite agora dissociar 
o sob-êxito escolar vinculado à densidade urbana do que se deve especificamente à segregação. De fato, ambos os fenômenos não são necessariamente vinculados. Nas metrópoles densas menos segregadas, os sob-êxitos são nitidamente menos marcados. Portanto, é mesmo a segregação que desempenha um papel perturbador nas aprendizagens escolares (Broccolichi \& Sinthon, 2010).

A segunda perspectiva é a que tive a oportunidade de desenvolver no prolongamento desta pesquisa e dos meus trabalhos consagrados às trajetórias escolares dos alunos no ensino público e privado (Ben Ayed, 2000, 2001). Buscava explorar a seguinte questão: uma vez que conseguimos estabelecer que, nos territórios escolares submetidos a fortes lógicas de concorrência, as aprendizagens escolares são mais fracas e as desigualdades mais marcadas, em virtude da intensificação de práticas de évitement scolaire, podemos discernir o impacto dessas desvantagens escolares nas trajetórias escolares longas? É o que conseguimos mostrar com a ajuda de uma análise estatística longitudinal, enfocando o estudo dos vínculos entre escolhas de escola e trajetórias escolares. Fica claro que os alunos que não mudaram de estabelecimento têm trajetórias escolares mais favoráveis. Em outras palavras, esta pesquisa comprova que a escolha da escola é mais frequentemente associada a situações de crise do que às perspectivas de maximização do capital escolar (Ben Ayed, 2011). Obviamente, este último caso não é totalmente ausente, mas, estudado em ampla escala, com coortes representativas de alunos, é minoritário. Estes resultados, parcialmente específicos à situação francesa, dificilmente poderiam ser generalizados a outros países, nos quais as estratificações escolares são ainda mais marcadas do que na França e a possibilidade de escapar do estabelecimento escolar mais próximo do domicílio permitiria favorecer o acesso a oportunidades educativas mais proveitosas (Ribeiro et al., 2010). A convergência dessas constatações mostra que, hoje em dia, é impossível ocultar a problemática local e os efeitos territoriais para pensar a questão das desigualdades de escolarização, assim como as margens de manobra políticas e institucionais para poder agir sobre as suas causas.

\section{Notas}

1. Conjunto das práticas adotadas pelas famílias para escolarizarem seus filhos em outra escola que não esteja na área de matrícula na qual se localiza o seu domicílio.

2. N. do T.: Num processo que se estendeu de 2002 a 2007, a França acabou adotando o sistema LMD (Licence - Master - Doctorat), que designa os três únicos diplomas universitários, no intuito de se conformar com as terminologias usadas em nível europeu e mundial. Entretanto, para quem estudou antes, o que é o caso dos pais dos alunos considerados nesta pesquisa, diferentes diplomas sancionavam os estudos universitários a partir do segundo ano do que aqui chamaríamos de "graduação". Como estes também mudaram de nome ao longo da história e das reformas, para simplificar, os franceses passaram a usar " $b a c+X$ ", em que bac significa baccalauréat (diploma de fim do ensino médio) e X designa o número de anos de estudos superiores correspondendo ao diploma. Na medida em que o autor usa essa terminologia no original, optamos por mantê-la na tradução. 
3. N. do T.: CAP = Certificat d'Aptitude Professionnelle (Certificado de Aptidão Profissional - três anos de estudos profissionais após a $6^{\underline{a}}$ série); $\mathrm{BEP}=$ Brevet d'Études Professionnelles (Diploma de Estudos Profissionais - três anos de estudos profissionais após a $8^{a}$ série); BEPC $=$ Brevet d'Études du Premier Cycle (Diploma de Conclusão do Fundamental II).

4. O que representa um quarto dos departamentos franceses. Nos outros três quartos, os desvios em relação à média nacional são bastante fracos ou negativos.

5. N. do T.: A França metropolitana é divida em 26 "circunscrições de ensino", chamadas "académies", cada qual levando o nome da(s) cidade(s) mais importante(s).

6. N. do T.: Principal região administrativa francesa, inclui Paris e os oitos departamentos que circundam a capital.

7. Para aprofundar esse ponto, ver Mathey-Pierre e Larguèze (2010).

8. N. do T.: Na França, o ensino médio é dividido em três categorias: econômica e social (ES), literária (L) e científica (S). A $1^{\mathrm{e}}$ corresponde ao segundo ano do ensino médio.

9. N. do T.: DDASS = Direction Départementale des Affaires Sanitaires et Sociales (Direção Departamental dos Assuntos Sanitários e Sociais). CAF = Caisse d'Allocations Familiales (Caixa de Auxílio às Famílias).

10. Os elementos apresentados aqui são muito sintéticos. Para um aprofundamento dessa monografia, ver Ben Ayed (2009b).

\section{Referências}

BEN AYED, C. Familles populaires de l'enseignement public et privé, caractéristiques secondaires et réalités locales. Éducation et Société, Paris, n. 5, p. 81-89, 2000.

BEN AYED, C. Savoir, vouloir, pouvoir: choix scolaires et désillusions des familles populaires. Revue Questions Educatives, Paris, n. 20, Puse, 2001.

BEN AYED, C. (Coord.). Ecole ségrégative, école reproductive. Actes de la Recherche en Sciences Sociales, Paris, n. 180, 2009a.

BEN AYED, C. Solidarités ouvrières et réussite scolaire dans la Loire. In: BEN AYED, C. Le nouvel ordre éducatif local: mixité, disparités, luttes locales. Paris: PUF, 2009b.

BEN AYED, C. A qui profite le choix de l'école ?: changements d'établissement et destins scolaires des élèves de milieux populaires. Revue Française de Pédagogie, Paris, n. 175, 2011.

BEN AYED, C.; BROCCOLICHI, S. Hiérarchisation des espaces scolaires, différenciations usuelles et processus cumulatifs d'échecs. Ville Ecole Intégration Enjeux, n. 127, 2001.

BEN AYED, C.; BROCCOLICHI, S. Que sait-on des liens entre réussite scolaire, inégalités sociales et lieu de scolarisation? Ville École Intégration Diversite, n. 155, déc. 2008.

BEN AYED, C.; BROCCOLICHI, S. Les inégalités socio-spatiales d'accès aux savoirs, In: VAN ZANTEN, A.; DURU-BELLAT, M. (Dir.). Sociologie du système éducatif: les inégalités scolaires. Paris: PUF, 2009. 
BEN AYED, C.; BROCCOLICHI, S.; TRANCART, D. Les inégalités socio-spatiales d'éducation: processus ségrégatif, capital social et politiques territoriales. Paris: MEN; DEP; Datar, 2006. (Rapport de recherche appel à projet Education et Formation: disparités territoriales et régionales).

BEN AYED, C.; BROCCOLICHI, S.; TRANCART, D. (Coord.). École: les pièges de la concurrence; comprendre le déclin de l'école française. Paris: La découverte, 2010.

BROCCOLICHI, S. Inégalités cumulatives, logique de marché et renforcement des ségrégations scolaires. Ville Ecole Intégration, n. 114, 1998.

BROCCOLICHI, S.; SINTHON, R. Libre choix, hiérarchisation des espaces scolaires et surcroît d'échecs, In: BEN AYED, C. (Dir.). L'école démocratique: vers un renoncement politique? Paris: Armand Colin, 2010.

BROCCOLICHI, S.; SINTHON, R. Comment s'articulent les inégalités d'acquisition scolaire et d'orientation ?: relations ignorées et rectifications tardives. Revue Française de Pédagogie, Paris, n. 175, 2011.

DELVAUX, B.; VAN ZANTEN, A. Les établissements scolaires et leur espace local d'interdépendance. Revue Française de Pédagogie, Paris, n. 156, 2006.

FRANCE. Conseil Économique et Social Environnemental. Les inégalités à l'école. Paris: Journal Officiel de la République Française, 2011.

FRANÇOIS, J.C.; POUPEAU, F. Le sens du placement scolaire: ségrégation résidentielle et ségrégation scolaire. Paris: Raisons d'Agir, 2008.

LES INÉGALITÉS D'ÉDUCATION: un classique revisité. Education et Sociétés, Paris, n. 5, 2000/1.

MAROY, C. Ecole, régulation et marché: une comparaison de six espaces scolaires locaux en Europe. Paris: PUF, 2006.

MATHEY-PIERRE, C.; LARGUEZE, B. Désarroi des familles, des élèves et des professionnels. In: BEN AYED, C.; BROCCOLICHI, S.; TRANCART, D. (Coord.). École: les pièges de la concurrence. Comprendre le déclin de l'école française. Paris: La Découverte, 2010.

MAURIN, E. La nouvelle question scolaire: les bénéfices de la démocratisation. Paris: Seuil, 2007.

MEURET, D.; LAMBERT, M. La dégradation de l'équité de l'école française dans les années 2000. Revue Française de Pédagogie, Paris, n. 177, oct./ déc. 2011.

OBERTI, M. L'école dans la ville: ségrégation- mixité - carte scolaire. Paris: Presses Universitaires de Sciences Po, 2007. 
OEUVRARD, F. La construction des inégalités de scolarisation de la maternelle au lycée. In: VAN ZANTEN, A. (Org.). L'école l'état des savoirs. Paris: La Découverte, 2000.

ORGANISATION FOR ECONOMIC CO-OPERATION AND DEVELOPMENT (OCDE). Pisa 2009 results. Paris: OCDE, 2010. v. 4.

PAYET, J.P. Collèges de banlieue: ethnographie d'un monde scolaire. Paris: Méridiens Klinsieck, 1995.

RIBEIRO, L.C.Q. et al. (Org.). Desigualdades urbanas, desigualdades escolares. Rio de Janeiro: Letra Capital, 2010.

THIN, D. Quartiers populaires: l'école et les familles. Paris: Presses Universitaires de Lyon, 1998.

VAN ZANTEN, A. L'école de la périphérie: scolarité et ségrégation en banlieue. Paris: PUF, 2001.

Recebido em 10 de junho de 2012.

Aprovado em 14 de agosto de 2012. 